\title{
O rafting na perspectiva de um projeto interdisciplinar com o Ensino Médio
}

\section{integrado}

\author{
Rafting from the perspective of an interdisciplinary project with integrated High School \\ Rafting desde la perspectiva de un proyecto interdisciplinario con Escuela Secundaria integrado
}

Recebido: 28/12/2020 | Revisado: 30/12/2020 | Aceito: 05/01/2021 | Publicado: 07/01/2021

Larissa Beraldo Kawashima
ORCID: https://orcid.org/0000-0002-2613-9647
Instituto Federal de Educação, Ciência e Tecnologia de Mato Grosso, Brasil
E-mail: larissa.kawashima@ cba.ifmt.edu.br
Fabiane de Mesquita Batista
ORCID: https://orcid.org/0000-0001-7893-4397
E-mail: fabiane.batista @ cba.ifmt.edu.br
Paulo Daniel Curti de Almeida
Instituto Federal de Educação, Ciência e Tenologia de Mato Gross, Brasil
ORCID: https://orcid.org/0000-0001-9211-3704
E-mail: paulo.almeida @ cba.ifmt.edu.br
Monica dos Santos Spinelli
Instituto Federal de Educação, Ciência e Tenologia de Mato Grosso, Brasil
ORCID: https://orcid.org/0000-0002-2096-0311
Enstituto Federal de Educação, Ciência e Tecnologia de Mato Grosso, Brasil
E-mail: monica.spinelli @ cba.ifmt.edu.br

\section{Resumo}

Este artigo tem por objetivo relatar a experiência com a elaboração e execução de um projeto interdisciplinar para turmas do $2^{\circ}$ ano do Ensino Médio Integrado, na visão dos professores envolvidos no processo, tendo como tema gerador a vivência do rafting (esporte radical). A experiência se configura como qualitativa-descritiva, sendo o lócus da experiência as aulas do Curso Técnico em Secretariado Integrado ao Ensino Médio do IFMT - Campus Cuiabá Cel. Octayde Jorge da Silva. Os sujeitos foram os alunos matriculados nas duas turmas de $2^{\circ}$ ano do ano letivo de 2019, somando-se 76 alunos envolvidos. A apresentação dos dados seguiu os caminhos percorridos na sequência pedagógica construída e executada, sendo constituída a partir da elaboração coletiva de um projeto interdisciplinar, o desenvolvimento dos conteúdos por cada disciplina envolvida, os desafios para a execução do projeto, a vivência do rafting e a avaliação interdisciplinar.

Palavras-chave: Interdisciplinaridade; Rafting; Prática docente; Ensino médio.

\begin{abstract}
This article aims to report the experience with the elaboration and execution of an interdisciplinary project for classes of the 2nd year of integrated high school, in the view of the teachers involved in the process, having as a generator theme the experience of rafting (extreme sport). The experience is configured as qualitative and descriptive, with the locus of experience being the technical courses in a secretariat integrated to the high school of IFMT - Campus Cuiabá Cel. Octayde Jorge da Silva. The subjects were students enrolled in the two 2nd year classes of the 2019 school year, totaling 76 students involved. The presentation of the data followed the paths taken in the pedagogical sequence constructed and executed, being constituted from the collective elaboration of an interdisciplinary project, the development of the contents for each discipline involved, the challenges for the execution of the project, the experience of rafting and the interdisciplinary evaluation.
\end{abstract}

Keywords: Interdisciplinarity; Rafting; Teaching practice; High school.

\section{Resumen}

Este artículo tiene como objetivo reportar la experiencia con la elaboración y ejecución de un proyecto interdisciplinario para las clases del $2^{\circ}$ año de Escuela Secundaria Integrado, a la vista de los docentes involucrados en el proceso, teniendo como tema generador la experiencia del rafting (deporte extremo). La experiencia se configura como cualitativo-descriptiva, siendo el locus de experiencia las clases del Curso Técnico en Secretaría Integrada a Escuela Secundaria en IFMT - Campus Cuiabá Cel. Octayde Jorge da Silva. Los sujetos fueron alumnos matriculados en las dos clases de 2o curso del curso 2019, totalizando 76 alumnos implicados. La presentación de los datos siguió los caminos tomados en la secuencia pedagógica construida y ejecutada, constituyéndose a partir de la elaboración colectiva de un proyecto interdisciplinario, el desarrollo de los contenidos para cada disciplina involucrada, los desafíos para la ejecución del proyecto, la experiencia del rafting y la evaluación interdisciplinaria.

Palabras clave: Interdisciplinariedad; Rafting; Práctica docente; Escuela secundaria. 


\section{Introdução}

As exigências nas diferentes esferas das sociedades capitalistas implicam situações complexas no cotidiano das atividades profissionais para as quais as disciplinas convencionais não se encontram preparadas. A interdisciplinaridade escolar obriga o professor a rever suas práticas e a redescobrir seus talentos uma vez que as noções, finalidades, habilidades e técnicas visam favorecer especialmente o processo de aprendizagem, respeitando os saberes dos alunos e sua integração (Fazenda, 2008).

Para Zabala (1998, p. 143) a interdisciplinaridade consiste na interação entre duas ou mais disciplinas, podendo ser uma simples comunicação de ideias até a influência mútua dos "conceitos fundamentais e da teoria do conhecimento, da metodologia e dos dados da pesquisa. Estas interações podem implicar transferências de leis de uma disciplina para outra e, inclusive, em alguns casos dão lugar a um novo corpo disciplinar”. Sendo assim, “[...] a interdisciplinaridade implica um diálogo entre os campos dos saberes, em que cada componente acolhe as contribuições dos outros, ou seja, há uma interação entre eles" (Brasil, 2019, p. 18).

A interdisciplinaridade contribui para que os principais objetivos da escola sejam atingidos, destacando a formação de sujeitos capazes de produzir a democratização da sociedade, consistindo na conquista das condições materiais, sociais, políticas e culturais, possibilitando, assim, a participação ativa de todos na sociedade (Libâneo, 1994). Assim, a escola precisa propiciar ações para que os alunos adquiram autonomia e os possibilitem serem agentes críticos e transformadores de sua realidade, sendo que essa tarefa só surtirá efeito se houver um processo de construção conjunta, provendo-os de fundamentos teóricos e práticos que os permitam compreender a relevância e amplitude das mais diversas áreas de conhecimento (Correia, 2011; Moreira; Pereira \& Lopes, 2009).

Neste sentido, a prática pedagógica do professor é elemento importante para a concretização dos processos pedagógicos que corroboram os objetivos da escola, pois são "práticas que se organizam intencionalmente para atender a determinadas expectativas educacionais solicitadas/requeridas por dada comunidade social” (Franco, 2012, p. 154).

[...] uma prática pedagógica é formada por um conjunto complexo e multifatorial. O professor em sala de aula atua com base em decisões já tomadas ou não; com base em convicções já estruturadas ou não. Reitero que - por serem expansivas, por se "infiltrarem" na cultura de forma a estruturar sua legitimação, por se aninharem em práticas já existentes - as práticas pedagógicas requerem adesão, negociação e, em alguns casos, imposição [...] (Franco, 2012, p. 156).

A partir das práticas pedagógicas, a prática docente é transformada na sala de aula, e não o contrário, e isso pode ser bom ou ruim. "A sala de aula organiza-se pela teia de práticas pedagógicas que a envolve e com ela dialoga” (Franco, 2012, p. 159). Para a prática docente ser prática pedagógica - pois nem sempre correspondem - é necessário que esteja inserida na intencionalidade prevista para sua ação, ou seja, o professor precisa saber o sentido de sua aula para o aluno, que integra e expande sua formação, que tem consciência das ações propostas, preocupa-se com o aprendizado do aluno, é um professor com responsabilidade social e tem sua prática docente pedagogicamente fundamentada. Esse professor

[...] insiste, busca, dialoga, mesmo que não tenha muitas condições institucionais para tal. Dei um nome a isso: professor encontra-se em constante vigilância crítica (grifo da autora). Fica quase atormentado por essa vigilância. Esse professor não consegue simplesmente "dar a lição" nem mais pensar nisso. Ele está lá, testando e refletindo. Pois bem, essa é uma prática docente que elabora o sentido de prática pedagógica. É prática que se exerce com finalidade, planejamento, acompanhamento, vigilância crítica, responsabilidade social. Perguntam-me sempre: com teoria? E eu procuro demonstrar que o professor que age dessa maneira tem concepções teóricas sobre seu fazer pedagógico. Ele não está nesse momento aplicando uma prática de forma mecânica e burocrática; ao contrário, está coordenando a prática com sua teoria da aprendizagem. Esta teoria pode ser ultrapassada, equivocada? Sim, pode ser; no entanto, há convicção, empenho, coerência didática (Franco, 2012, p. 160-161).

Para Franco (2012), ao construir sua prática pedagógica, o professor está em contínuo processo de diálogo com o que 
faz, porque faz e como deve fazer. A dinâmica de construção e reconstrução da prática, do refazer, criar novas possibilidades, é o que faz sua prática uma prática pedagógica.

Ainda, estas práticas pedagógicas podem ser consideradas como inovadoras em relação às práticas existentes no contexto da cultura escolar em que se insere. Betti \& Zuliani (2002) compreendem que no estreitamento das relações entre teorias e práticas pedagógicas, "inovar" significa experimentar novos modelos, estratégias, metodologias, conteúdos, para que a Educação siga contribuindo para a formação integral dos jovens e para a apropriação crítica da cultura contemporânea.

Este artigo tem por objetivo relatar a experiência com a elaboração e execução de um projeto interdisciplinar para turmas do $2^{\circ}$ ano do Ensino Médio integrado, na visão dos professores envolvidos no processo, tendo como tema gerador a vivência do rafting (esporte radical).

\section{Metodologia}

Este artigo se configura como um relato de experiências em que são descritas todas as etapas do projeto executado. A experiência se configura como qualitativa-descritiva, pois segundo Lüdke e André (1986) supõe o contato direto e prolongado do pesquisador com o ambiente e a situação que está sendo investigada, via de regra, através do trabalho intensivo de campo. O lócus da experiência são as aulas do curso técnico em secretariado integrado ao ensino médio do IFMT - Campus Cuiabá Cel. Octayde Jorge da Silva, sendo os sujeitos os alunos matriculados nas duas turmas de $2^{\circ}$ ano do ano letivo de 2019, somando 76 alunos envolvidos.

A apresentação dos dados seguirá os caminhos percorridos na sequência pedagógica construída e executada, sendo constituída a partir da elaboração coletiva de um projeto interdisciplinar, o desenvolvimento dos conteúdos por cada disciplina envolvida, os desafios para a execução do projeto, a vivência do rafting e a avaliação interdisciplinar. O projeto foi elaborado e desenvolvido durante o segundo semestre do ano letivo de 2019.

\section{A Elaboração do Projeto Interdisciplinar}

\subsection{O desenvolvimento das aulas pelos professores envolvidos}

As atividades de aventura têm uma relação próxima com o meio natural, possibilitando aos praticantes um contato aproximado com a natureza, como a

[...] importância dada ao conhecer o clima, ou o tempo, como é encontrado em muitos relatos de praticantes, indica não só uma relação direta com o meio, mas também o caráter criativo de um mundo em constante transformação (Zimmermann, 2006). Talvez aqui encontremos o principal atrativo das atividades de aventura, expresso na possibilidade de se integrar com a natureza - por mais que seja de forma temporária -, caracterizando uma alternativa concreta para indivíduos que anseiam por um afastamento temporário dos grandes centros urbanos com o intuito de recarregar as energias para retomar as tarefas do cotidiano (Badaró et. al., 2020, p. 8).

Sendo assim, nas aulas de Educação Física, os objetivos propostos para a disciplina correspondem ao conteúdo de "esportes radicais", sendo eles: conhecer os procedimentos de segurança no rafting e caminhada de pequeno curso; vivenciar um esporte radical de aventura, no meio aquático. As aulas ministradas seguiram a seguinte sequência didática de conteúdos: 1) conceitos de esportes radicais, suas classificações quanto ao meio (terrestre, aquático, aéreo ou misto) e a divisão em esportes de ação - exigem a técnica, ou seja, habilidades específicas como as manobras, como exemplo o skate - e esportes de aventura pressupõem a imprevisibilidade da atividade, devido ao ambiente em que ocorrem serem abertos, ligados à natureza $\mathrm{e}$ sujeitos às intempéries do mesmo - exemplo do próprio rafting, em que podem acontecer chuvas fortes durante o percurso e modificar toda as estratégias da atividade (Pereira, Armbrust \& Ricardo, 2008); 2) Aulas práticas de esportes de ação: skate, slackline, rapel, parkour e surfe; 3) conceitos e diferenças entre "risco", "perigo" e risco procurado pelos "praticantes de 
esportes radicais" (Le Breton, 2009); 4) exibição e discussão do filme "Caçadores de emoção: além do limite" (2016), que apresenta atletas de esportes radicais ao extremo, em cenas de surf em ondas gigantes, wingsuit e até escalada em paredões sem utilização de nenhum equipamento de segurança; 5) Aula prática de esportes de aventura: vivência do rafting.

Para a Geografia, a prática do rafting condicionou-se a associação de atributos naturais em determinado recorte espacial, especificamente a condição do relevo e a influência deste na hidrografia. Para o plano de ação em voga, utilizou-se como base o córrego Tenente Amaral, no município de Jaciara-MT. Ele deságua no rio São Lourenço que é afluente do Rio Cuiabá. Observa-se que esse conjunto de águas tem como ponto de encontro a planície do Pantanal Mato-grossense. Conforme Maitelli (2005) o córrego faz parte da sub-bacia do rio São Lourenço (Grande Bacia Platina). A atividade de rafting se fez por um percurso de aproximadamente 2500 metros, sendo que a origem da ação se deu nas proximidades da cachoeira da Fumaça, no ponto $\left(15^{\circ} 58^{\prime} 48.35^{\prime \prime S}\right.$; $54^{\circ} 59^{\prime} 26.23^{\prime \prime O}$ e elevação de $\left.249 \mathrm{~m}\right)$ e finalizou-se nas proximidades do ponto $\left(15^{\circ} 59^{\prime} 6.72\right.$ "S; $54^{\circ} 58^{\prime} 12.41^{\prime \prime} \mathrm{O}$ e elevação de 244 metros).

Como apontado a declividade no percurso observado foi de 5 metros. Levando-se em consideração os dois pontos referenciados anteriormente e suas respectivas coordenadas geográficas, é possível afirmar que a área utilizada está situada, do ponto de vista geomorfológico, em área de planalto em bacia sedimentar e na estrutura do Planalto dos Alcantilados (Miranda; Bastos, 2016). Por fim, reitera-se a simbiose disponível (e necessária) no recorte espacial observado, fato que permitiu a realização da atividade de rafting, a partir da sua idealização até a sua vivência.

Em Biologia, as aulas contemplaram os objetivos de estimular a percepção dos impactos da prática de esportes radicais nos sistemas do corpo humano (sistema nervoso, sistema circulatório, sistema respiratório, sistema límbico e outros); reconhecer as fitofisionomias do bioma Cerrado; compreender a importância da biodiversidade de fauna, flora e microrganismos desse Bioma e ainda, sensibilizar os estudantes para cuidado com o Ambiente. Antes da viagem os conceitos teóricos foram trabalhados em sala de aula já no contexto do local a ser visitado e os alunos foram orientados sobre a conduta e regras em aulas de campo. Na vivência, os alunos observaram ao longo do trajeto dos impactos socioeconômicos nas fitofisionomias do bioma Cerrado e na trilha puderam reconhecer e compreender a diferença entre briófitas, pteridófita e angiospermas. Observar associações ecológicas como líquens; o papel das plantas na alimentação de pequenos animais encontrados e microrganismos. E por fim, puderam sentir os efeitos da prática do rafting no aumento dos batimentos cardíacos os hormônios endorfina, adrenalina e dopamina.

Nas turmas de segundo ano, a disciplina de Sociologia abordou o conteúdo sobre a percepção do "eu" e o "outro" através do fenômeno da alteridade, na perspectiva antropológica. Vislumbrou-se aspectos da diversidade cultural existente entre a espécie humana, fazendo o exercício de nos reconhecermos como uma cultura possível dentre tantas outras (LaPlantine, 2002). Foram abordadas explicações teóricas em relação a unidade biológica e a diversidade cultural presentes na humanidade, tais como determinismo biológico e geográfico, chegando a ideia de relativismo cultural e do particularismo histórico reconhecidos durante o processo de construção da própria Antropologia Social como ciência.

A experiência do rafting trouxe o fenômeno da alteridade de maneira viva e concreta para o conteúdo abordado em sala de aula ao demonstrarmos que outras lógicas sociais são possíveis para além da vivenciada em ambientes urbanos. A vivência em um ambiente com contato direto com a natureza pôde ainda sensibilizá-los em relação às questões socioambientais, a reflexão sobre a sociedade de consumo atual e a mercantilização do lazer. Finalmente, ainda foi possível relacionar os impactos socioeconômicos e ambientais existentes no Mato Grosso oriundos do agronegócio e as propostas de construções de Pequenas Centrais Hidrelétricas (PCHs)s na região e a relação desses processos em grupos e sociedades tradicionais e seus recursos naturais. 


\subsection{Os desafios para execução do projeto}

O rafting é um esporte oferecido por empresas especializadas, pois necessita de equipamentos de segurança, treinamento e atender as normas de certificação Brasileira do Turismo de Aventura. Sendo assim, o primeiro desafio é encontrar uma empresa de confiança para oferecer o serviço de forma segura para os alunos e professores do campus. A empresa contratada foi da cidade de Jaciara-MT, devido a professora de Educação Física integrante do projeto já ter oferecido a atividade em outro campus por oito anos em parceria com essa empresa. Para tanto, foi necessário um trabalho em equipe entre alunos e professores para arrecadar o valor correspondente à contratação da atividade, necessitando de um gerenciamento de recursos para arrecadação do mesmo através de vendas de pizzas.

Outro desafio foi a mudança da cultura escolar do campus, em que práticas pedagógicas inovadoras contextualizadas e coerentes com os objetivos educacionais não eram comuns, ou seja, o processo de elaboração e construção de uma proposta interdisciplinar como esta não era comum, já que as visitas técnicas configuravam-se mais como passeios e lazer do que atividades pedagógicas. Neste sentido, professores que nem ministravam aula para as turmas envolvidas solicitaram participação na atividade, como forma de "passear". Foi preciso deixar bem claro os objetivos educacionais do projeto, principalmente para a gestão do campus e para os pais/responsáveis pelos alunos.

O processo burocrático para realização da vivência do rafting foi outro ponto desafiador a ser gerenciado, pois foram necessárias autorização dos pais (alunos menores de idade), solicitação de ajuda de custo para os estudantes, processo de reserva dos ônibus na instituição, gestão financeira dos recursos para a realização da atividade, contato com a empresa responsável pelo rafting, reuniões coletivas e individuais com pais de alunos e elaboração coletiva do projeto interdisciplinar para avaliação da equipe pedagógica.

A construção coletiva com os professores de diversas áreas foi outro desafio, principalmente em relação a gestão dos horários para encontros e reuniões para discussão e elaboração do projeto. Porém, esta etapa pode ser considerada como uma das mais ricas, considerando-se como um processo de formação de continuada docente, de construção coletiva de aprendizagem com o outro, de reflexão sobre nossas concepções e práticas pedagógicas.

$\mathrm{E}$ ainda, os desafios socioemocionais de relacionamento interpessoal entre os estudantes, que exigiram papel de mediação dos professores junto alguns estudantes e/ou pais, que estavam com medo. Outro desafio foi a organização dos grupos de estudantes e de professores para transporte no ônibus e descidas durante a vivência do rafting

\subsection{A vivência do rafting}

O rafting é realizado na cidade de Jaciara, MT, distante $140 \mathrm{~km}$ do campus. Desta forma, a logística consistiu em um local de apoio para aqueles que não estivessem realizando a atividade, no caso, foi escolhido um balneário com estrutura de lazer próximo ao local da prática do rafting, que oferece almoço aos participantes. Os custos incluem "day use no balneário + almoço + rafting", no valor de R $\$ 150$ reais por pessoa pagos com trabalho dos alunos de venda de pizza.

No dia 16/10/2019 saímos do campus às 7h30, chegando ao balneário por volta das 10h30. Imediatamente os alunos se dividiram em três grupos, sendo que um realizou o rafting antes do almoço e os outros dois grupo às $13 \mathrm{~h}$ e às $15 \mathrm{~h}$. O rafting teve duração de 2 horas, entre instrução sobre a atividade e equipamentos de segurança, deslocamento, trilha até o rio, banho no rio e cachoeira, rafting (descida, momento para surf, quedas) e deslocamento de volta ao balneário. Passamos o dia em Jaciara e retornamos às $17 \mathrm{~h}$. Para os alunos, esse não é apenas um momento de aprendizagem, aliás, de forma prazerosa permitem-se vivenciar a prática e sentir todos benefícios e assim, dar significado ao processo de aprendizagem tornando-o inesquecível na vida do estudante. As Figuras 1 e 2 ilustram a vivência do rafting. 
Research, Society and Development, v. 10, n. 1, e18210111562, 2021

(CC BY 4.0) | ISSN 2525-3409 | DOI: http://dx.doi.org/10.33448/rsd-v10i1.11562

Figura 1. Vivência do rafting.

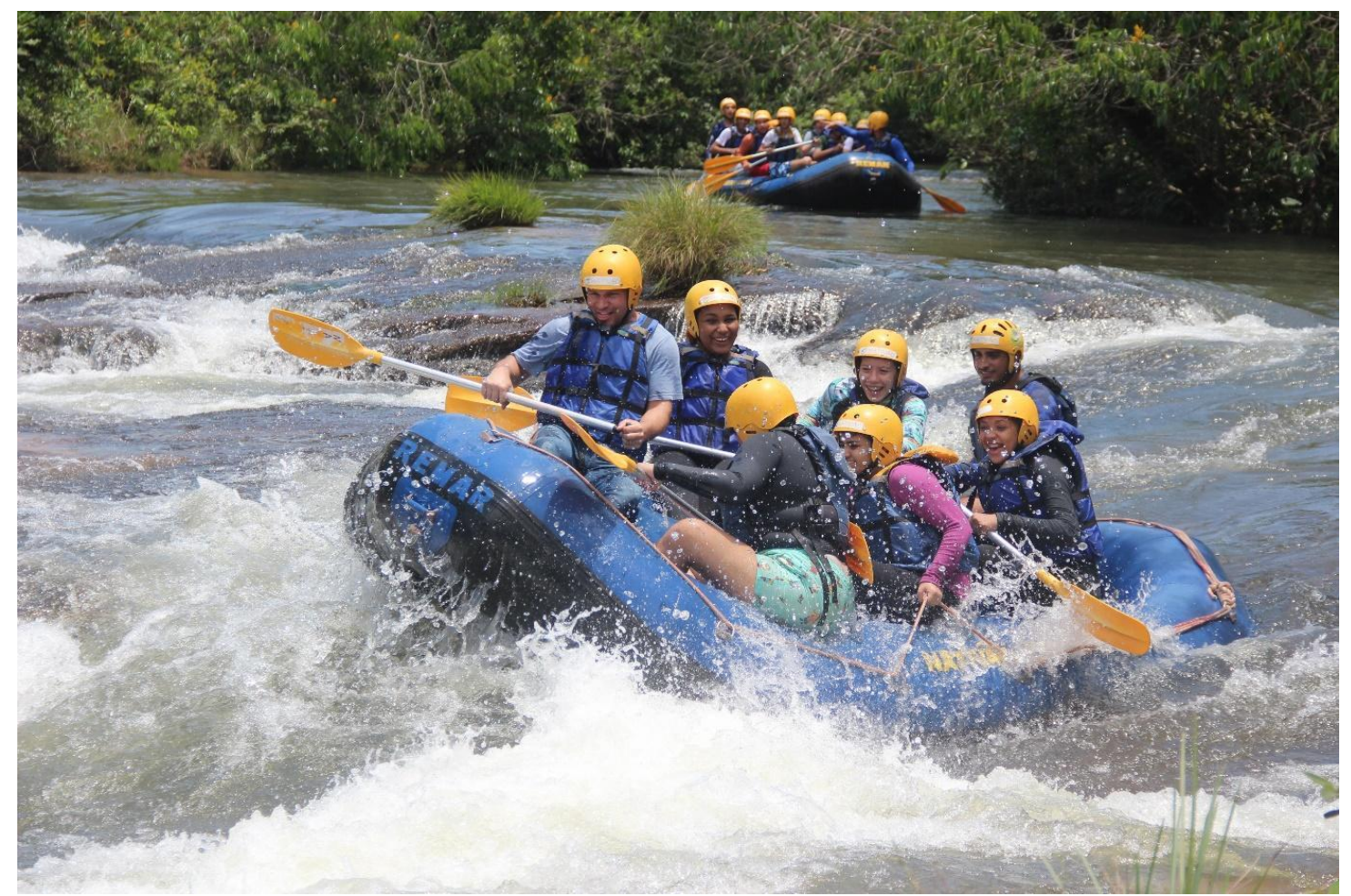

Fonte: Nativão.

Na Figura 1 acima é possível identificar dois botes com alunos e professores durante a vivência do rafting, num trecho do rio com corredeiras nível 1 de dificuldade (fácil), exigindo pouca técnica dos participantes.

Figura 2. Vivência do rafting.

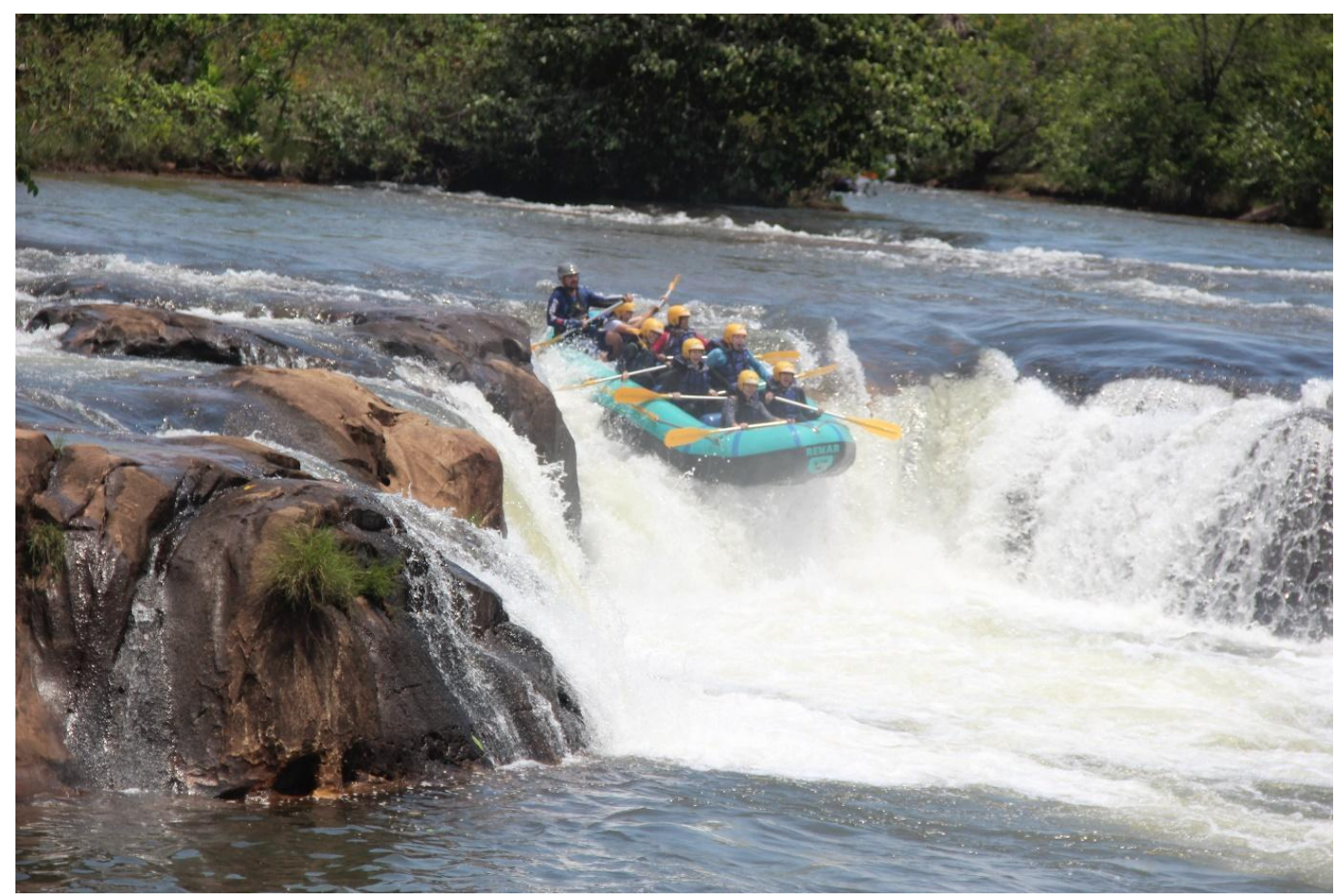

Fonte: Nativão. 
A Figura 2 ilustra a última e maior corredeira do percurso, considerada de nível 3 (intermediária), com altura de 3 metros, exigindo dos participantes um pouco mais de técnica para que possam transpô-la com mais tranquilidade e minimizando os riscos.

\subsection{Avaliação interdisciplinar}

A avaliação interdisciplinar seguiu um roteiro elaborado pelos professores e apresentado previamente aos alunos, conforme o Quadro 1 a seguir:

Quadro 1. Roteiro para atividade interdisciplinar de vivência de sensibilização do rafting.

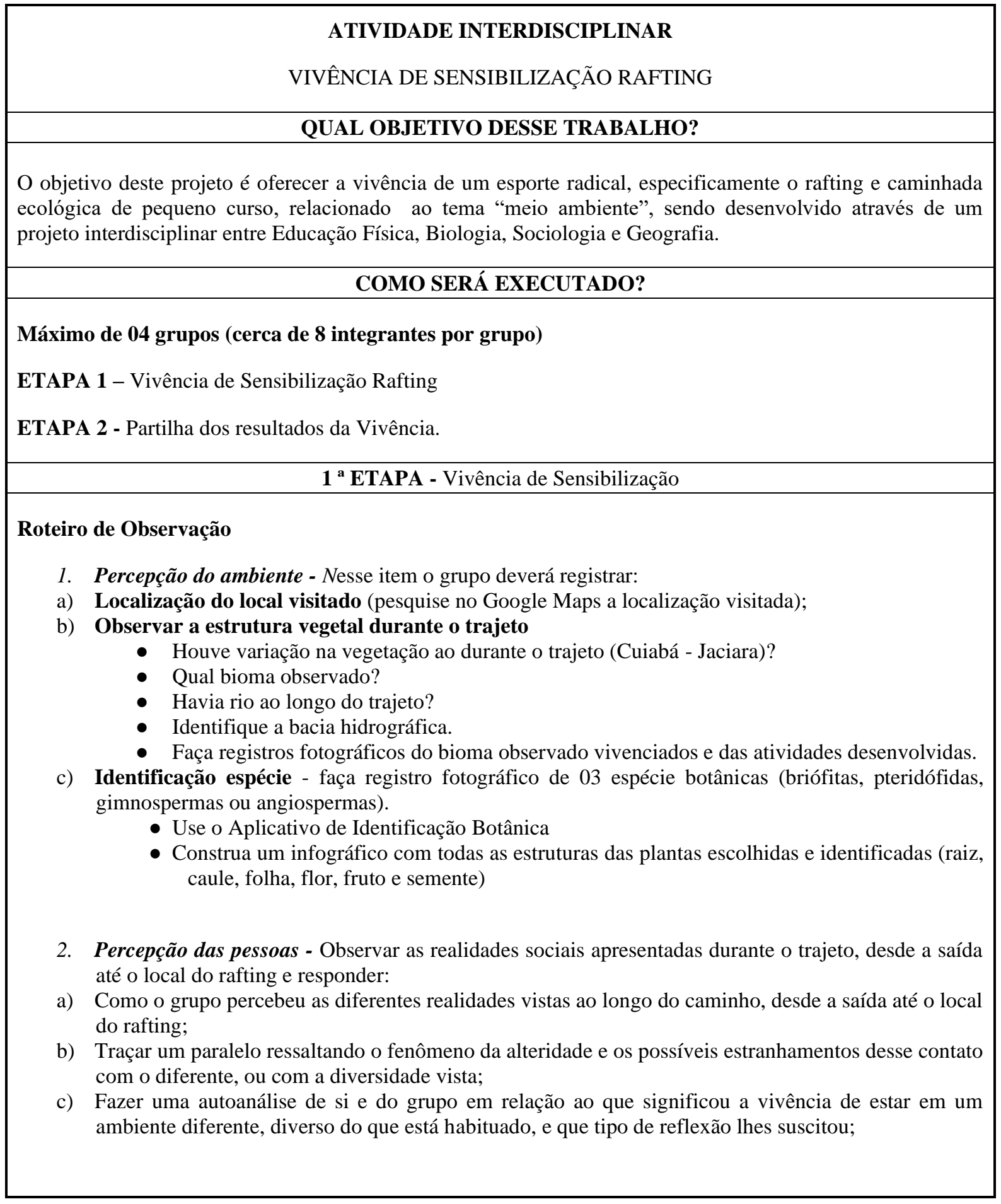




\section{Percepção sobre a vivência do rafting}

a) O rafting é classificado como um esporte radical de "aventura". Explique sobre esta classificação a partir da experiência vivenciada.

b) Equipamentos de segurança: quais os equipamentos de segurança disponibilizados pela empresa e qual sua função durante a atividade? Você se sentiu seguro com estes equipamentos? Explique.

c) Quais as técnicas/movimentos necessários para a realização do rafting?

4. Percepção Sociemocional - Diversas reações químicas ocorrem no corpo humano enquanto praticamos um exercício físico.

a) Descreva a sensação, emoção e o grau de "risco físico" vivenciado durante o rafting - lembrando que essa percepção é subjetiva (individual) e varia para cada sujeito. O grupo deverá montar uma tabela, e apresentar o sentimento vivido por cada participante do grupo.

b) Pesquise sobre endorfina, adrenalina e dopamina. Explique o que são essas substâncias, como agem no nosso corpo com a prática de esportes radicais.

\section{ETAPA - Intercâmbio de Conhecimento}

- Cada grupo fará uma apresentação de 20 minutos com as percepções da vivência.

\section{- Data apresentação:}

2A Secretariado - 30/10/2019

2B Secretariado - 01/11/2019

Fonte: Autores.

Os alunos foram orientados a se organizarem em grupos e a se orientarem pelo roteiro durante a atividade, desde a saída do campus, o percurso da viagem, a trilha e a vivência do rafting, até o retorno ao campus. Os alunos tiveram cerca de quinze dias para preparação do da apresentação, não sendo necessário a entrega do relatório. As apresentações, em formato de seminários em grupo, foram acompanhadas e avaliadas pelos professores das quatro disciplinas conjuntamente, sendo a nota final composta pela soma dos itens avaliados na $1^{\mathrm{a}}$ etapa, conforme quadro 2.

Quadro 2. Avaliação interdisciplinar das apresentações.

\begin{tabular}{|c|c|c|c|c|c|}
\hline $\begin{array}{c}\text { ORDEM } \\
\text { APRESENTAÇÕES }\end{array}$ & A & B & C & D & $\mathbf{E}$ \\
\hline $\begin{array}{l}\text { PERCEPÇÃO AMBIENT) } \\
\text { (Valor } 0 \text { a 2,5 ) }\end{array}$ & & & & & \\
\hline $\begin{array}{l}\text { PERCEPÇÃO PESSOAS } \\
\text { (Valor } 0 \text { a 2,5 ) }\end{array}$ & & & & & \\
\hline $\begin{array}{l}\text { PERCEPÇÃO RAFTING } \\
\text { (Valor } 0 \text { a 2,5 ) }\end{array}$ & & & & & \\
\hline $\begin{array}{l}\text { PERCEPÇÃO } \\
\text { SOCIOEMOCIONAL } \\
(\text { Valor } 0 \text { a } 2,5 \text { ) }\end{array}$ & & & & & \\
\hline NOTA FINAL & & & & & \\
\hline
\end{tabular}

Fonte: Autores.

Após as apresentações, os professores se reuniram para dialogar sobre os trabalhos apresentados, verificando se todos os itens propostos no roteiro foram contemplados. É importante destacar a aprendizagem docente nesse processo avaliativo, em 
que cada professor participou da "escuta" do outro, aprendendo com o outro a partir das relações estabelecidas entre os saberes de sua disciplina em diálogo com as demais. A relação do saber, a partir de Charlot (2000), demonstra a atribuição de sentidos ao projeto, interligando os saberes e estabelecendo relações entre os conhecimentos de cada disciplina consigo mesma, com as outras disciplinas e com a aprendizagem para a vida, com o mundo.

\section{Considerações Finais}

A experiência interdisciplinar relatada neste texto apresentou caminhos possíveis para a implementação de tais práticas curriculares, com ações que mobilizam alunos e professores num processo de ensino-aprendizagem mais significativo. A Base Nacional Comum Curricular - BNCC (2017, p. 16), destaca a importância de ações curriculares que decidam "sobre formas de organização interdisciplinar dos componentes curriculares e fortalecer a competência pedagógica das equipes escolares para adotar estratégias mais dinâmicas, interativas e colaborativas em relação à gestão do ensino e da aprendizagem".

As experiências diferenciadas durante as aulas de Educação Física, Geografia, Sociologia e Biologia, que provocam sensações novas ou vivências antes não imaginadas, como a vivência do rafting, constitui-se em experiências capazes de transformar o próprio sentido das aulas para os alunos, pois são momentos em que precisam mobilizar os conhecimentos apreendidos em sala para uma situação nova, compartilhando e usufruindo desses conhecimentos em situações reais e problematizadoras. Os alunos se sentem valorizados e valorizam a atividade. A atividade interdisciplinar passa a ter importância para eles.

Além de estimular áreas cognitiva durante a aprendizagem e revisitar conceitos teóricos vistos em sala, a prática permitiu desenvolver habilidade socioemocionais como: planejamento, organização e compromisso para obtenção dos recursos financeiros para vivência; diálogo e comunicação empática na resolução dos problemas; relação interpessoal auxiliando os colegas na venda de pizza, durante a trilha ou na prática do rafting; flexibilidade e habilidade intrapessoal para maturidade de suas próprias emoç̃es diante de todos os desafios desde venda de pizzas, viagem e vivência do rafting.

Vê-se que a partir de uma experiência prática e vivencial foi possível aproximar conceitos teóricos de diferentes disciplinas, aproximá-los da realidade concreta, fomentar o prazer em aprender e participar ativamente do processo de aprendizagem tanto para os estudantes, quanto para os professores. Tais habilidades são importantes para a formação humana e profissional na perspectiva dos discentes que estão sendo preparados para atuarem no mundo e no mundo do trabalho. Porém também reafirmam entre os professores envolvidos seu compromisso por uma prática reflexiva e ética de uma atuação comprometida com a formação do outro e de si mesmo em um processo dialógico e de crescimento. Assim, procuram elaborar uma prática pedagógica que faça sentido e ressignifique constantemente sua atuação, como afirma Franco (2012), com uma constante vigilância crítica, reafirmando a busca por caminhos e alternativas que toquem a si e ao outro, tangenciando e ampliando a compreensão e a leitura, a interpretação e a sua atuação do mundo.

Para finalizar, sugerimos que mais professores-pesquisadores se aventurem nos caminhos do trabalho interdisciplinar, compartilhando suas experiências nos diferentes meios de divulgação científica, pois a interdisciplinaridade aproxima o conhecimento das diferentes áreas e disciplinas, tornando-os compreensíveis e mais reais aos alunos.

\section{Referências}

Badaró, L. F., Oliveira, V. M. de., Mattes, V. V., Menegaldo, P. H. I., Reis, R. A. M. dos., Souza, N. B. da S., Brasil, M. R., \& Souza, J. de. (2020). Atividades de aventura no campo educacional: alternativas metodológicas para as aulas de Educação Física. Research, Society and Development, 9 (11), e749119352. https://doi.org/10.33448/rsd-v9i11.9352

Betti, M. \& Zuliani, L. R. (2002). Educação física escolar: uma proposta de diretrizes pedagógicas. Revista mackenzie de educação física e esporte. 1(1), 7381. 
Research, Society and Development, v. 10, n. 1, e18210111562, 2021 (CC BY 4.0) | ISSN 2525-3409 | DOI: http://dx.doi.org/10.33448/rsd-v10i1.11562

Brasil. (2019). Temas contemporâneos transversais na BNCC: contexto histórico e pressupostos pedagógicos. Ministério da Educação. Brasília, MEC. http://basenacionalcomum.mec.gov.br/images/implementacao/contextualizacao_temas_contemporaneos.pdf

Brasil. (2017). Base nacional comum curricular: Brasília: Ensino http://basenacionalcomum.mec.gov.br/images/BNCC_EI_EF_110518_versaofinal_site.pdf

Caçadores de emoção: além do limite. (2016). Direção de Ericson Core. Warner Bross (113 min.), DVD, son., color. Legendado.

Charlot, B. (2000). Da relação com o saber: elementos para uma teoria. Artes Médicas Sul.

Correia, W. R. Educação Física no ensino médio: questões impertinentes. (2a ed.), Fontoura.

Fazenda, I. C. A. Interdisciplinaridade: história, teoria e pesquisa. Papirus.

Franco, M. A. R. S. (2012). Pedagogia e prática docente. Cortez.

Laplantine, F. (2000). Aprender Antropologia. ed. Brasiliense.

Le Breton, D. (2009). Condutas de risco: dos jogos de morte ao jogo de viver. Autores Associados.

Libâneo, J. C. (1994). Didática. Cortez.

Maitelli, G. T. (2005). A hidrografia no contexto regional. In: Moreno, G. \& Higa, T. C. S. (Orgs.). Geografia de Mato Grosso: território, sociedade, ambiente. Entrelinhas, 272-287.

Miranda, L. \& Bastos, H. (2016). Atlas geográfico de Mato Grosso. (2a ed.), Entrelinhas.

Moreira, E. C., Pereira, R. S., Lopes, T. C. (2009). Desafios e propostas para a educação física no ensino médio. In: Moreira, E. C. \& Nista- Piccolo, V. L. (Orgs.). O quê e como ensinar educação física na escola. Fontoura, 177-197.

Pereira, D. W., Armbrust, I., \& Ricardo, D. P. (2008). Esportes radicais de aventura e ação: conceitos, classificações e características. Corpoconsciência. FEFISA, 12 (1), 37-55.

Zabala, A. (1998). A prática educativa: como ensinar. Artmed. 